JOURNAL OF THE SOUTH AFRICAN INSTITUTION OF CIVIL ENGINEERING ISSN 1021-2019

Vol 63 № 4, December 2021, Pages 24-34, Paper 1280

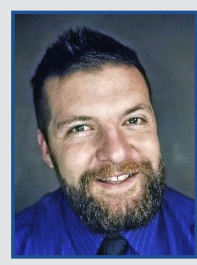

RUBEN VAN DER MERWE is a Candidate Civil Engineer who specialises in the field of structural engineering. He obtained his BIng Civil and part-time MEng Structural (with distinction) at the University of Johannesburg in 2015 and 2020, respectively. His main research interests are in the field of steel construction. He is

currently employed as Design Engineer at Structa Konsult, situated in the province of Gauteng.

Contact details:

Department of Civil Engineering

University of Johannesburg

P0 Box 524

Auckland Park 2006

South Africa

T: +27842499538

E: rubenvandermerwe24@gmail.com

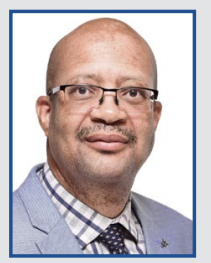

DR JEFFREY MAHACH is the Head of School of Civil Engineering and the Built Environment at the University of Johannesburg, and also a Director of the Sustainable Materials and Construction Technologies (SMaCT) Research Centre. He obtained his PhD in Civil Engineering from the University of the Witwatersrand, and his MSc in Structural Engineering from the University of Surrey, United Kingdom. He has previously held several executive positions at the National Home Builders Registration Council and worked as a Research Engineer at the CSIR. His research interests are in disruptive construction technologies and structural risks.

Contact details:

School of Civil Engineering and the Built Environment

University of Johannesburg

Johannesburg

South Africa

T: +27829049569

E:jmahachi@uj.ac.za

\title{
An investigation of South African low-income housing roof anchor systems
}

\author{
R Van der Merwe, J Mahachi
}

The current roof anchoring methods for houses in South Africa are described in the standard SANS 10400. The adequacy of these prescribed roof anchoring methods for low-income houses (LIHs) is questionable, due to several recently reported failures caused by strong winds. This study quantitively investigates the performance of the prescribed roof anchoring methods through numerical methods, and focuses on LIHs with light-weight roofs supported on single-leaf masonry walls. The masonry walls comprise either solid bricks or hollow cement blocks. The peak wind reaction forces that are expected to occur at the roof anchor systems were determined through a series of static analyses. Finite element analysis techniques were performed to predict the capacity of the roof anchor systems. The predicted resistance of the roof anchor systems was compared to the calculated peak wind reaction forces at the roof anchors to determine the adequacy of the roof anchor systems. The results of the research suggest that, for LIHs constructed from solid bricks, the prescribed roof anchor systems perform poorly under the expected South African strong wind climate. The results indicated that the roof anchors will pull out at peak basic wind speeds of between $27 \mathrm{~m} / \mathrm{s}$ and $32 \mathrm{~m} / \mathrm{s}$, and cracks will develop in the masonry prior to anchor pull-out. This study suggests that further research is required to develop adequate roof anchoring methods for LIHs with light-weight roofs, supported on solid brick walls, and that the relevant codes should be amended accordingly. Furthermore, the results showed that the prescribed roof anchor systems for LIHs constructed from hollow blocks performed well and were able to withstand the expected wind loads under the South African strong wind climate.

\section{INTRODUCTION}

South Africa has a huge housing backlog which is escalating continually. In 2018 the backlog was more than 2.3 million (Mahachi 2021). To eradicate the housing backlog, the South African government provides a housing subsidy to households earning less than R3 500 per month. The subsidies are used to construct houses commonly referred to as low-income houses (LIHs). Typically, such houses have a footprint of 36-60 square metres, and the roofs are constructed with lightweight corrugated sheets $(0.5 \mathrm{~mm}$ thick) anchored to the walling system. The structural integrity of South African LIHs is often reported as substandard, mainly as a result of poor workmanship and the use of poor-quality materials, as reported by many inhabitants (Zunguzane et al 2012).

About five devastating wind events occur annually in South Africa, causing damage to structures and leaving thousands of people homeless, as cited in Goliger (2002). Mahachi et al (2018) suggest that wind-induced damage to non-engineered structures, such as LIHs, in most cases is caused by wind speeds of about $30 \mathrm{~m} / \mathrm{s}$.
Blown-off roofs of LIHs during strong winds have been recognised in a study by Ogunfiditimi (2008). The roofs in such an event become flying objects with the potential of causing injury to (or death of) humans and damage to surrounding buildings and infrastructure. Also, the roofs and support walls rely on each other for lateral support. Failure of the roof, therefore, also compromises the structural integrity of the support walls. Figure 1 (Goliger 2002) shows an illustrative example of roof and wall damage of a LIH caused by strong winds. Due to the likelihood of roofs blowing off during strong winds, many informal shelters and LIHs use objects such as tyres, bricks, or other heavy objects to assist in securing the roof. Figure 2 (Mabuya \& Scholes 2020) shows an example of such a case.

The current methods for anchoring roofs are prescribed in the South African Standard SANS 10400-K (SANS 2015). A schematic illustration of the prescribed roof anchor methods for single-leaf masonry walls is provided in Figure 3.

This research aims to determine the adequacy of the currently prescribed roof 


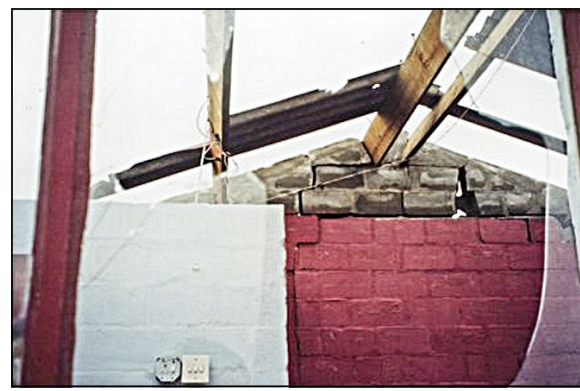

Figure 1 Damage of gable wall and failure of a roof caused by inadequate roof anchorage (Goliger 2002 - permission for re-use of photo granted)

anchors for South African LIHs under a strong wind climate and provides recommendations for further research on the topic. The aim was achieved through the following objectives:

- To determine the expected wind uplift reaction forces at the roof anchor system through static analyses.

- To predict the roof anchor system's performance against wind uplift through finite element analysis (FEA).

- To determine the roof anchor system's adequacy by comparing the peak reaction loads expected at the roof anchors to the predicted resistance offered by the roof anchor systems.

\section{METHODOLOGY}

The study was conducted through a quantitative research approach. The methodology of the research is divided into two main parts. The first part concerns the prediction of the peak wind reaction forces that are expected to occur at the roof anchor systems. The second part concerns the prediction of the roof anchor system's response. Figure 4 shows a flow diagram that outlines the methodology of the research. A detailed description of the steps is provided under the sub-headings that follow.

\section{Determination of the wind uplift reaction forces at the roof anchor system}

The reaction forces at the roof anchor systems were determined through a static FEA. Four distinct models representing typical LIHs with different roof configurations were defined. The models were designated as Model 1 to Model 4. The dimensions of the houses were kept constant, while the positions of the external openings, representing the front door and windows, were altered. The geometry of each model was based on typical LIHs in South Africa, as illustrated

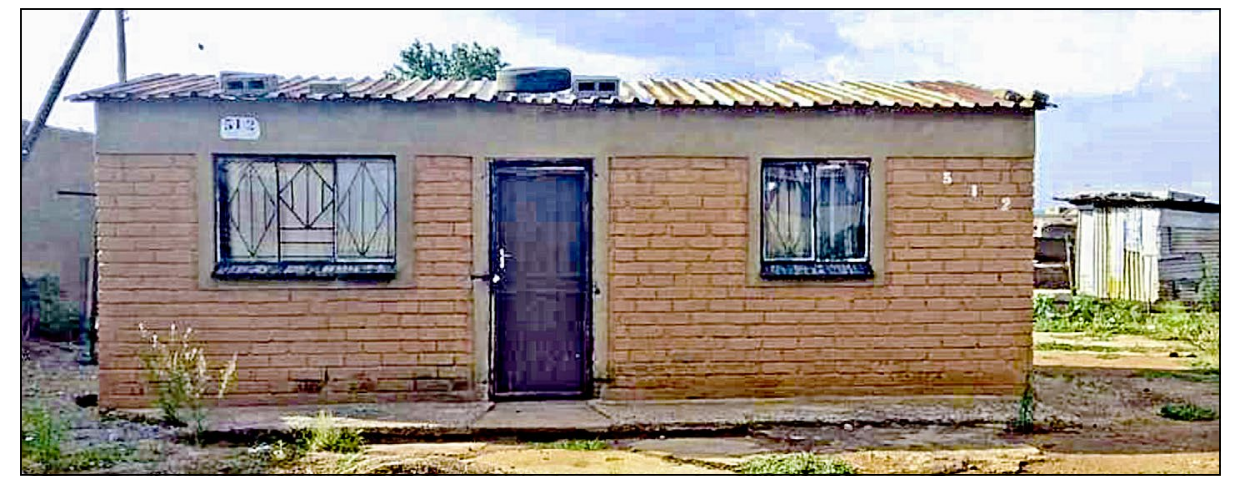

Figure 2 Illustration of heavy objects used to secure a roof of a LIH against wind uplift (Mabuya \& Scholes 2020 - photo reproduced here under the Creative Commons Attribution Licence)

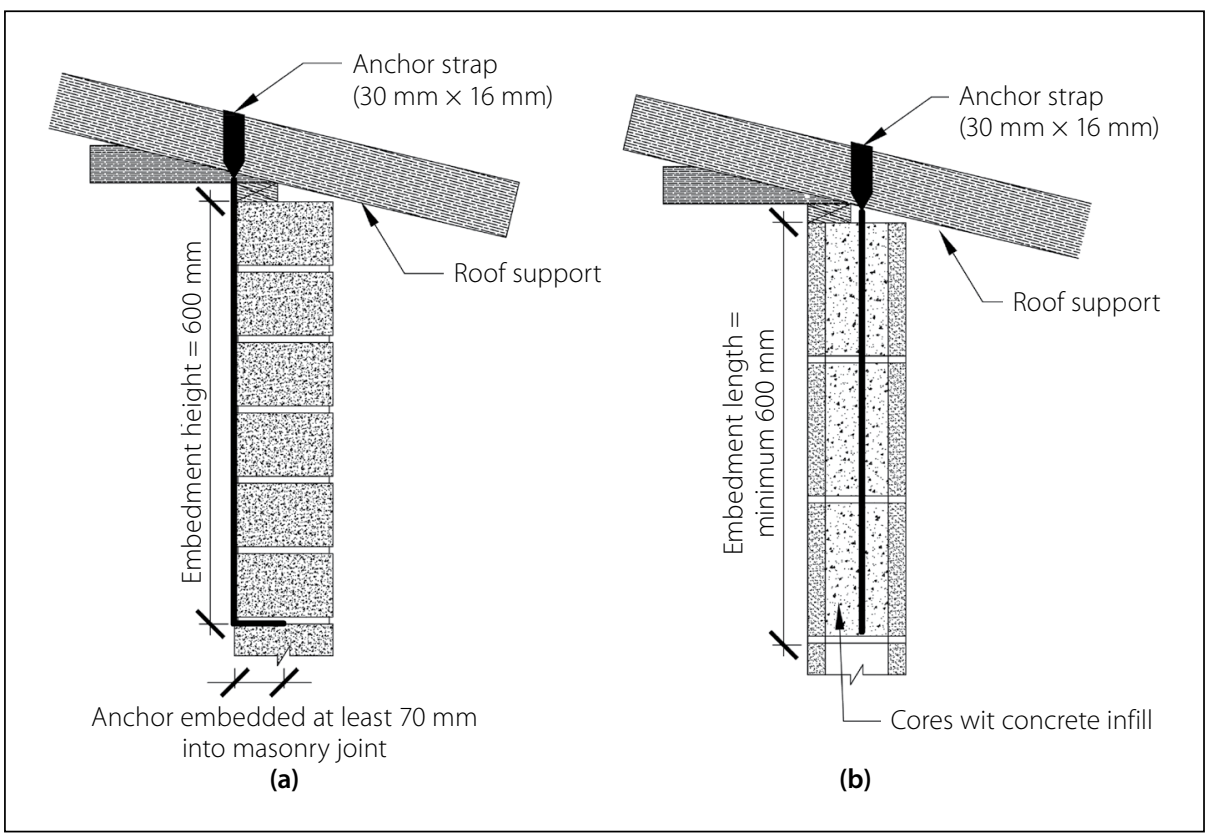

Figure 3 Prescribed roof anchoring methods for buildings with light roofs supported on singleleaf masonry: (a) solid-brick walls, (b) hollow-block walls (redrawn from SANS 2015)

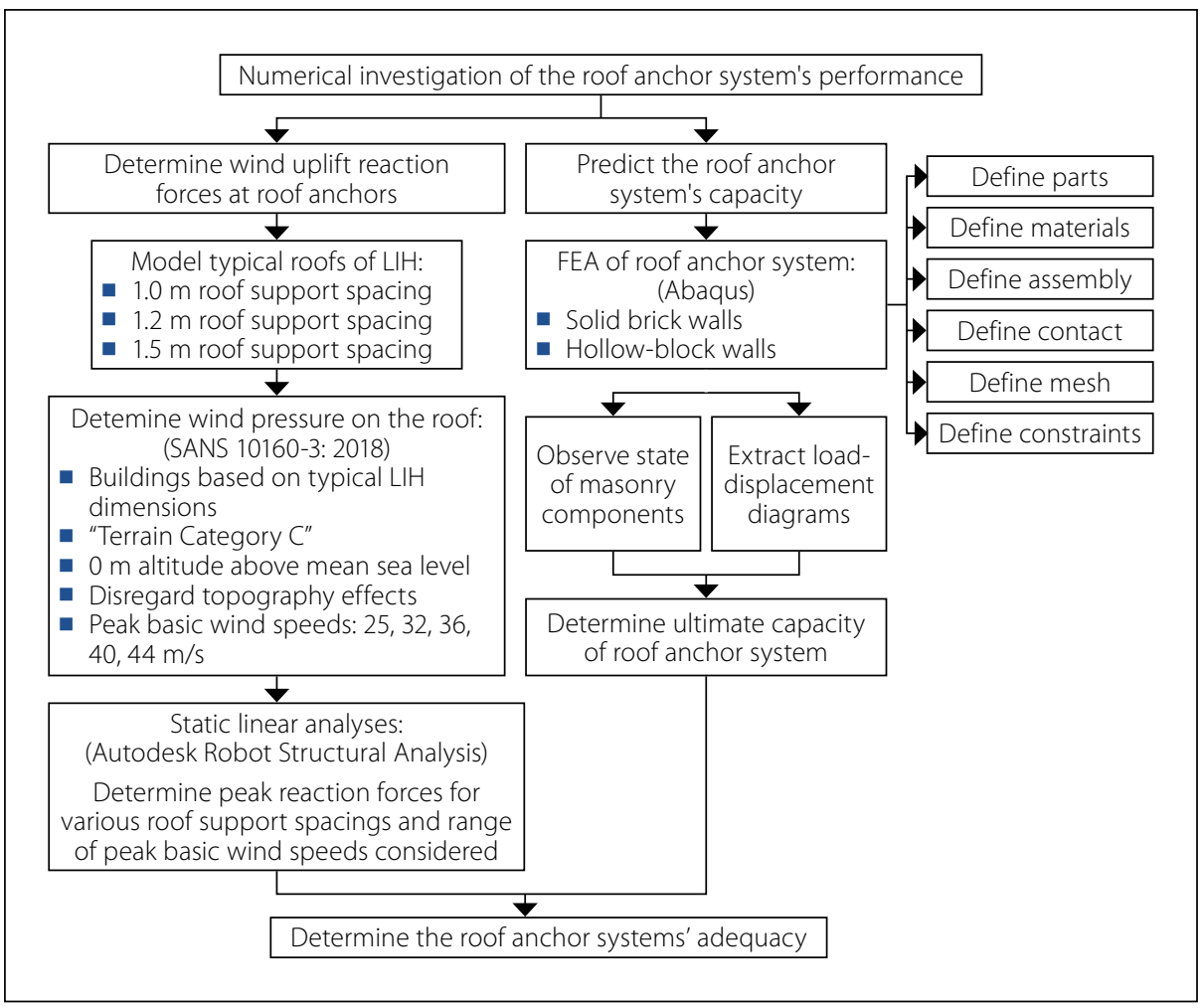

Figure 4 Outline of research methodology 
in Figure 5. The regulations from SANS 10400-K (SANS 2015) were utilised as a guideline to determine the dimensions of the LIH models. It was assumed that the front wall (for a single-storey house) will have openings of more than $15 \%$ of the total wall area and is therefore limited to a $6 \mathrm{~m}$ long by $2.7 \mathrm{~m}$ high wall panel for a $140 \mathrm{~mm}$ thick masonry wall. The sizes of the external walls were kept constant and hence resulted in a $6 \mathrm{~m}$ long by $6 \mathrm{~m}$ wide house with a height to the eaves of $2.7 \mathrm{~m}$. Truss or rafter spacings of $1.0 \mathrm{~m}, 1.2 \mathrm{~m}$, and $1.5 \mathrm{~m}$ were considered for each model. These spacings were chosen so that the length of the support walls is divisible by the roof spacing and, except for $1.5 \mathrm{~m}$ spacing, are within the range of the regulations of SANS 10400-L (SANS 2011), since the regulations limit the roof spacing to $1.4 \mathrm{~m}$. The roof slopes were taken as $12.5^{\circ}$ and $7^{\circ}$ for the duo-pitch and mono-pitch roofs, respectively. The roofs of the LIH models were modelled and analysed in Autodesk Robot Structural Analysis software due to its efficiency (in terms of time and effort) in simulating pressures on the roofs and determining the reaction forces. The roof anchor systems were resembled by defined support constraints. Resultant peak reaction forces were obtained for combined uplift wind loading and the self-weight of the roof structure and cladding.

The wind loading that acts on the roofs was calculated per the South African Standard SANS 10160-3 (SANS 2018). The wind direction and wind pressure calculations were based on the following parameters:

- The peak wind pressures were calculated for a range of 1 in 50-year basic wind speed values provided on the wind map in SANS 10160-3 (SANS 2018), i.e. $32 \mathrm{~m} / \mathrm{s}, 36 \mathrm{~m} / \mathrm{s}, 40 \mathrm{~m} / \mathrm{s}$ and $44 \mathrm{~m} / \mathrm{s}$. Also, a basic wind speed of $25 \mathrm{~m} / \mathrm{s}$ was introduced to broaden the range of wind speeds of the investigation.

- The terrain category defined as "Category C" per SANS 10160-3 (SANS 2018) was adopted to determine the peak wind pressures.

- Topography effects were ignored.

- An accidental load case was considered by assuming a dominant wall in the case where the openings on the windward wall of the house are open through the failure of the door and windows.

Figure 6 shows an illustrative example of the roof structure and wind pressure symbols, for Model 1, as modelled in Robot Structural Analysis software for wind at $0^{\circ}$.

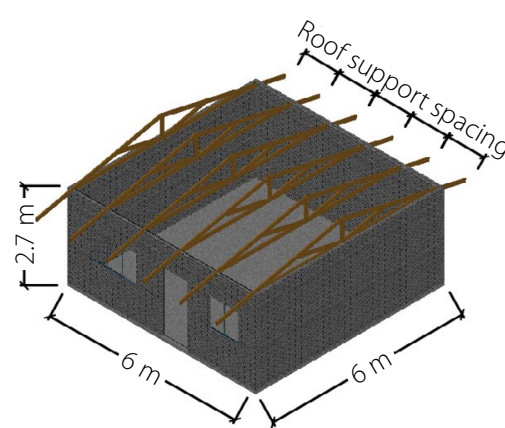

(a)

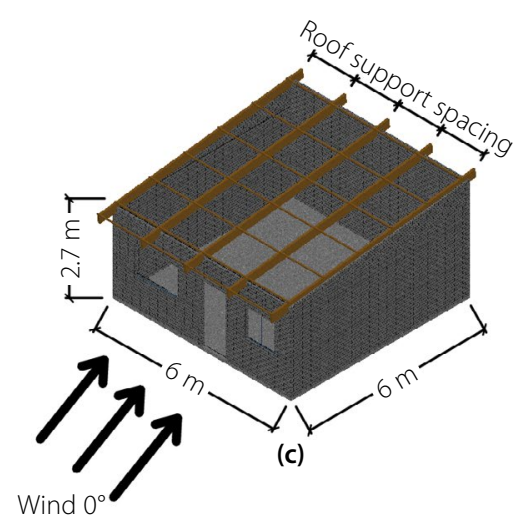

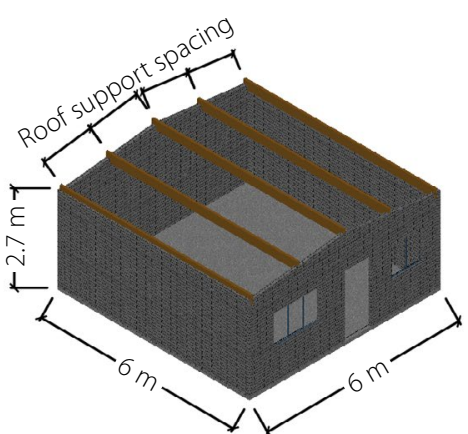

(b)

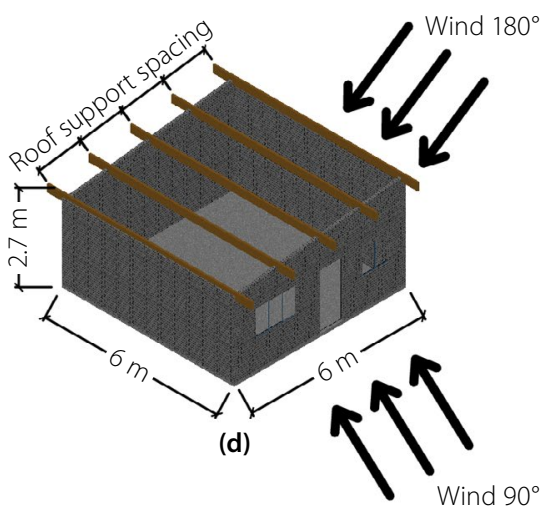

Figure 5 Wind loading directions and geometry of LIH models: (a) Model 1, (b) Model 2, (c) Model 3, and (d) Model 4

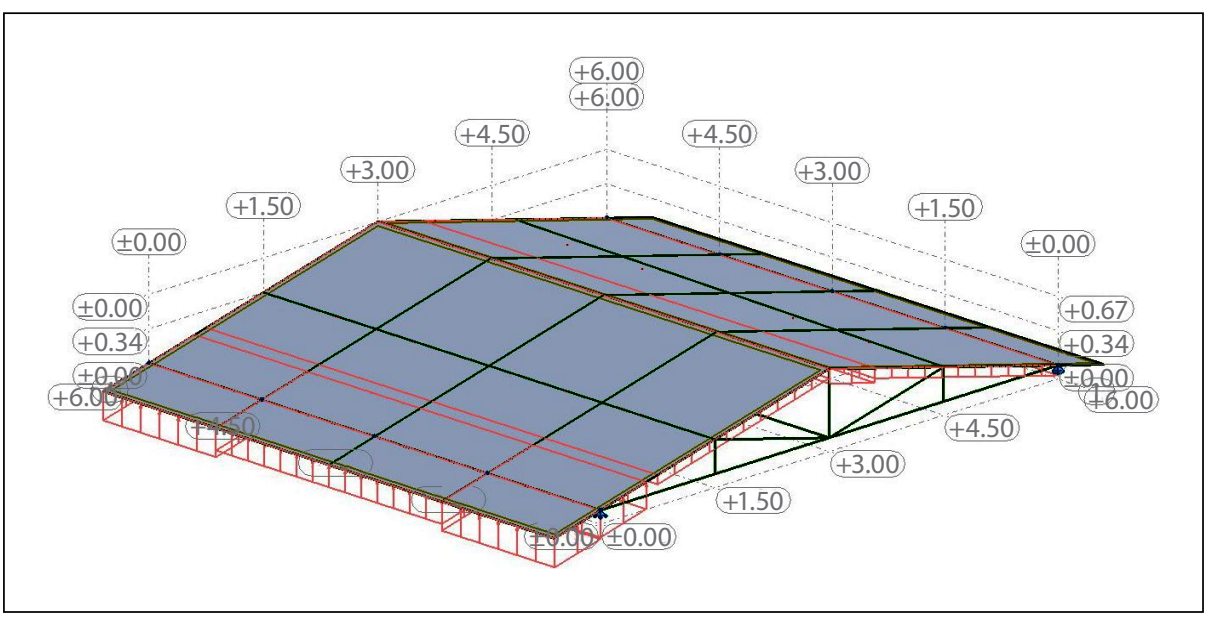

Figure 6 Illustrative example of net wind pressures applied to a roof structure

\section{Predicting the response and resistance of the roof anchor systems}

The resistances of the roof anchor systems were predicted through FEAs conducted in Abaqus software. Abaqus software was used due to its capability to model and solve complex engineering structures such as micro-modelling of masonry structures with contact simulation, as required for this study. The roof anchor systems were modelled and analysed to capture the capacity thereof due to simulations of the force applied, in turn due to uplift wind pressure on the roof. The pull-out capacities of the roof anchor systems were determined through load-displacement diagrams.
The modelling approach herein accounted for unit-mortar bond failure through defined surface contact interaction. Crushing and cracking of the masonry units and the mortar were accounted for by defined nonlinear behaviour of the Finite Elements (FEs) through the Concrete Damaged Plasticity (CDP) model. In this approach, a single part, referred to as a Representative Element (RE), was defined to represent a masonry unit, as well as one bed joint below and half the thickness of the head joints on either side of the masonry unit. The FE modelling approach is schematically presented in Figure 7. Through this modelling approach, the amount of contact is significantly reduced without compromising the accuracy of the model. 


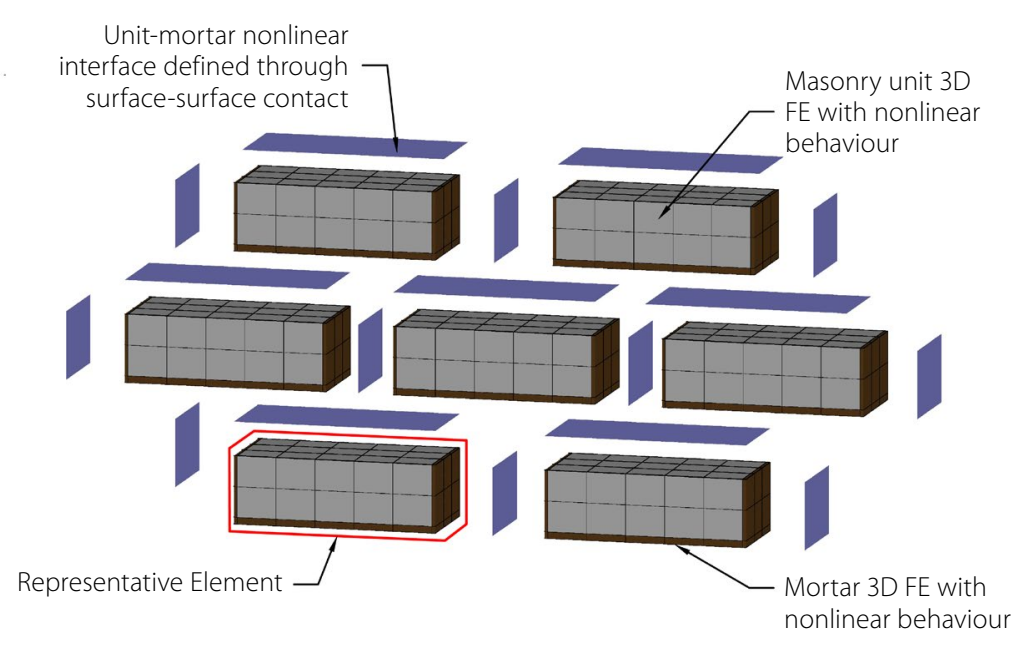

Figure 7 Approach adopted for FE modelling of masonry components

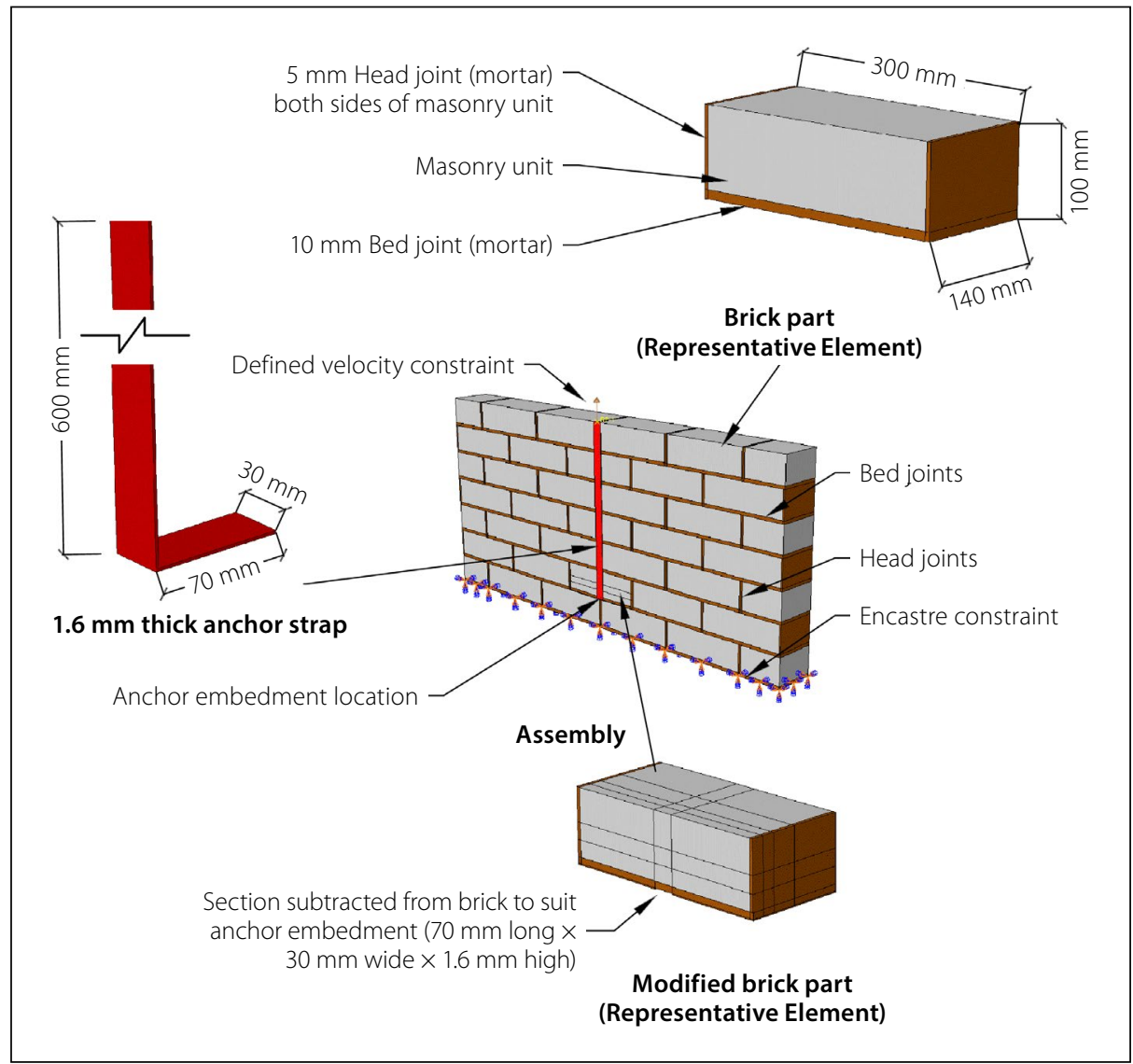

Figure 8 Assembly of FEA model representing the roof anchor system consisting of solid bricks

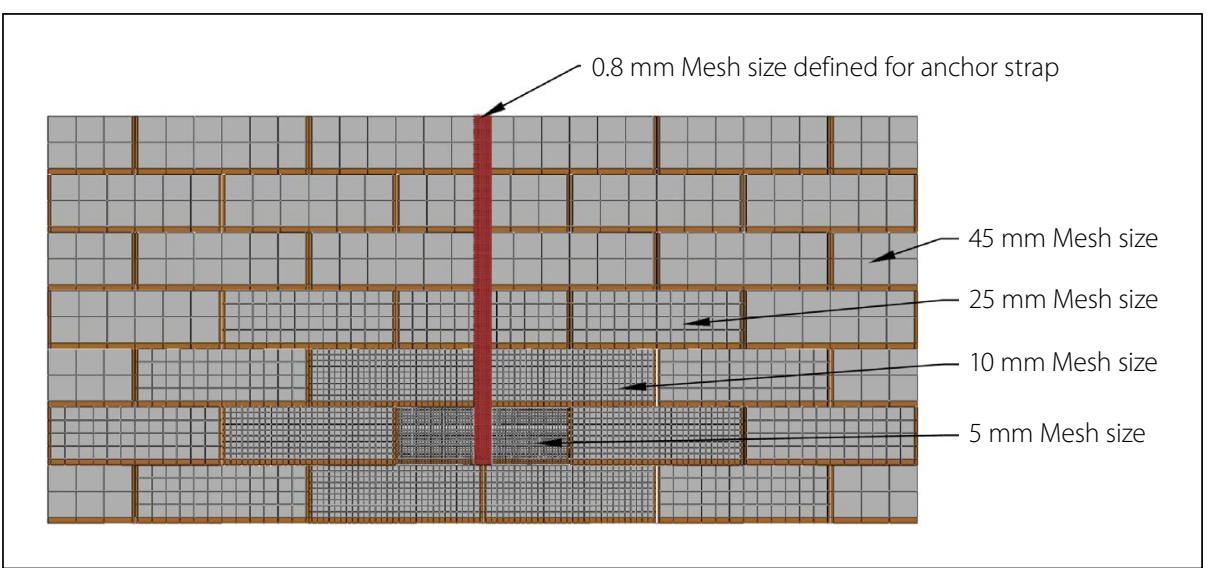

Figure 9 Mesh definition of the FEA model for the solid-brick wall
Modelling of roof anchor systems

The roof anchor systems concern the roof anchoring methods per SANS 10400-K

(SANS 2015) for single-leaf masonry walls. The dimension of the wall assembly was chosen to accommodate a result comparison to potential future physical testing.

The assembly of the FEA model for a roof anchor system consisting of a solid brick masonry wall is illustrated in Figure 8. A wall with dimensions of $1500 \mathrm{~mm}$ long, $700 \mathrm{~mm}$ high, and $140 \mathrm{~mm}$ thick was modelled. The parts were modelled using explicit 3D hexahedral-shaped, eight-node, linear brick elements with reduced integration and hourglass control (type C3D8R elements).

The anchor was embedded between two brick courses at the prescribed depth of $600 \mathrm{~mm}$ from the top of the wall. The brick situated on top of the anchor was modified by subtracting a region to suit the anchor embedment and is referred to as the modified RE. The bonding of the anchor to the mortar was simulated through defined surface-surface contact.

The bottom surface at the base of the wall was fully constrained against translation and rotation. A velocity constraint was applied to a reference point (RP), defined at the top of the anchor, to simulate an upwards "pulling" force. The imposed velocity produced a reaction force at the RP. Also, the RP was used to capture the magnitude of the vertical (uplift) reaction force throughout the loading period.

The mesh defined for the FEA model is presented in Figure 9. The brick elements in the vicinity surrounding the anchor embedment are expected to experience high-stress gradients due to the load being transferred from the anchor to the wall through the localised region. A refined mesh was introduced in the areas where high-stress gradients were expected. The mesh size was gradually increased towards the outer edges of the wall, where less focus was required, to effectively reduce the computational time.

Figure 10 shows a section through the wall indicating the modelling detail and meshing of the anchor embedment. A refined mesh was applied to the surfaces of the anchor strap involved in contact pair simulation with surfaces of the masonry components and was defined as the slave surface in the contact pair interactions.

A similar modelling approach was followed for the hollow-block masonry walls. A wall of $1650 \mathrm{~mm}$ long, $800 \mathrm{~mm}$ high and $140 \mathrm{~mm}$ thick was modelled as illustrated in Figure 11. A straight anchor was embedded 


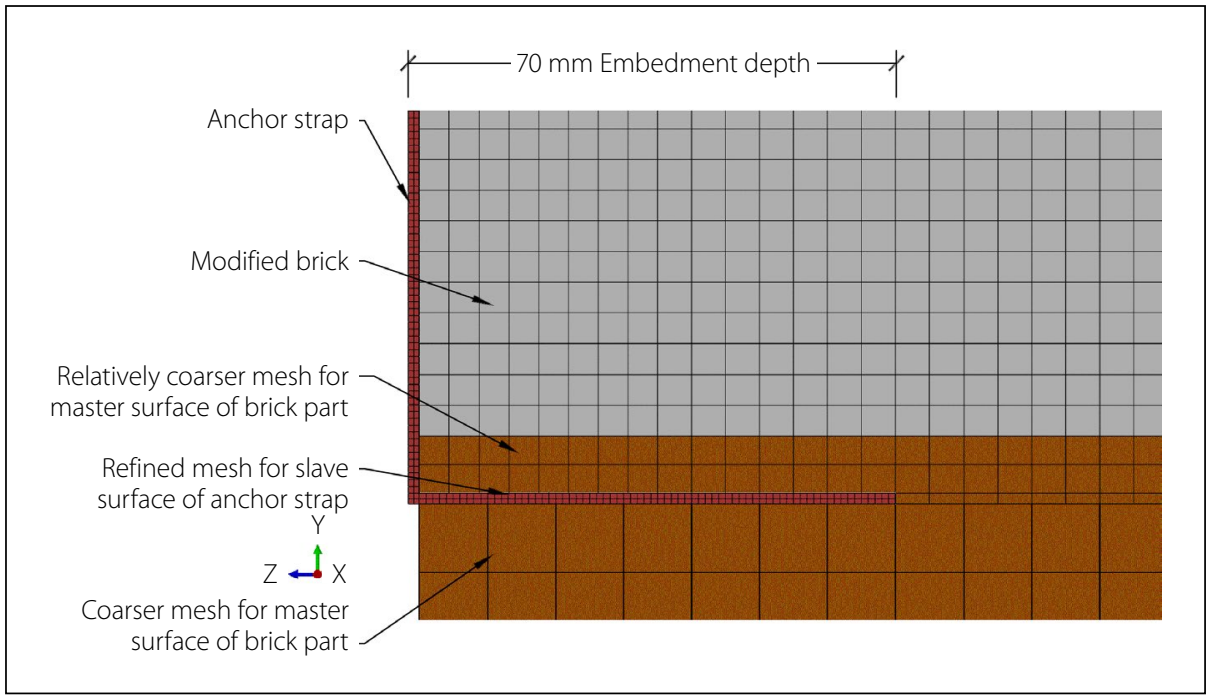

Figure 10 Section through a modified brick part showing the modelling detail for anchor embedment of a roof anchor system consisting of solid bricks

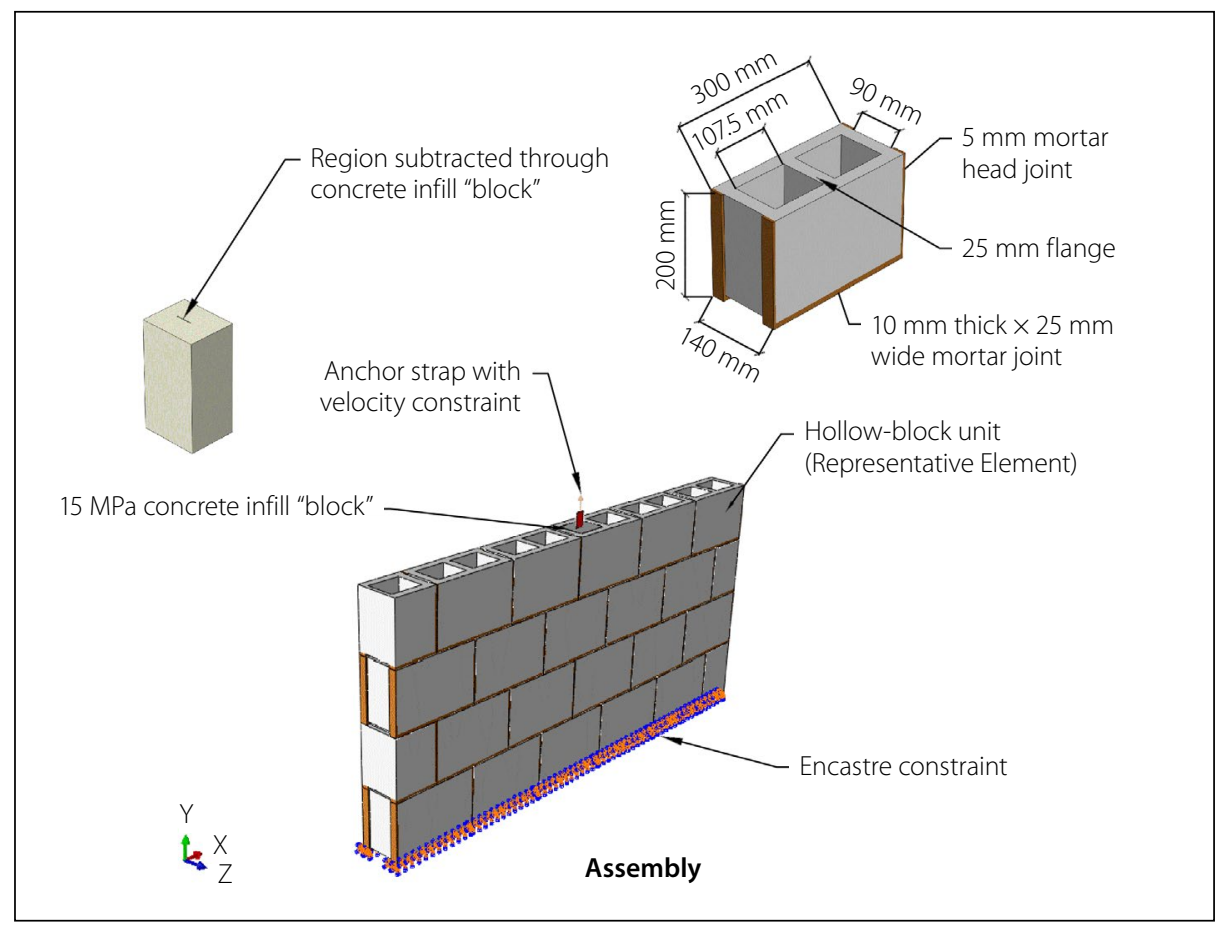

Figure 11 Assembly of FEA model that represents the roof anchor system consisting of hollow blocks
$600 \mathrm{~mm}$ into a concrete infill block with a hole subtracted through the block to suit the anchor embedment. The anchor bonding was simulated through a defined surface-surface contact interaction. The concrete infill block was placed continuously into the cores of the hollow blocks with cores that are vertically aligned near the roof support and connected through surface-surface contact interaction. Figure 12 shows a section through the wall indicating the anchor embedment detail of the FEA model. The mesh definition of the assembly model is illustrated in Figure 13.

For the FE modelling of the roof anchor systems, the brick-mortar interfacial bond properties are required, as well as the mechanical properties of the masonry units and mortar. For this study the interfacial bond properties are particularly important, since the loading of the roof anchors are expected to induce mainly tensile and shear stresses on the masonry wall. The bond strength of masonry is affected by various factors pertaining to masonry units, mortars and construction practice. The combined engineering properties of masonry, therefore, are scattered over a broad spectrum. Approximately realistic values for material properties should, however, be selected to ensure that the self-weight load effects and the overall stiffness are of the correct order. Masonry subjected to tensile and shear most often fails through the brick-mortar interface, especially in low bond strength masonry (Sarhosis et al 2015), which may be expected for this study due to the quality concerns of South African LIHs. The joint interface properties are, therefore, regarded to be of greater importance than the material properties of the units and mortar.

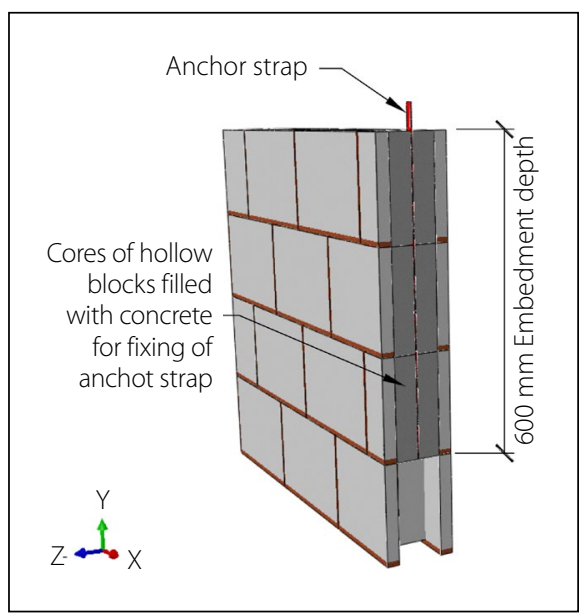

Figure 12 Section presenting the nature of the anchor embedment for the roof anchor system consisting of hollow blocks

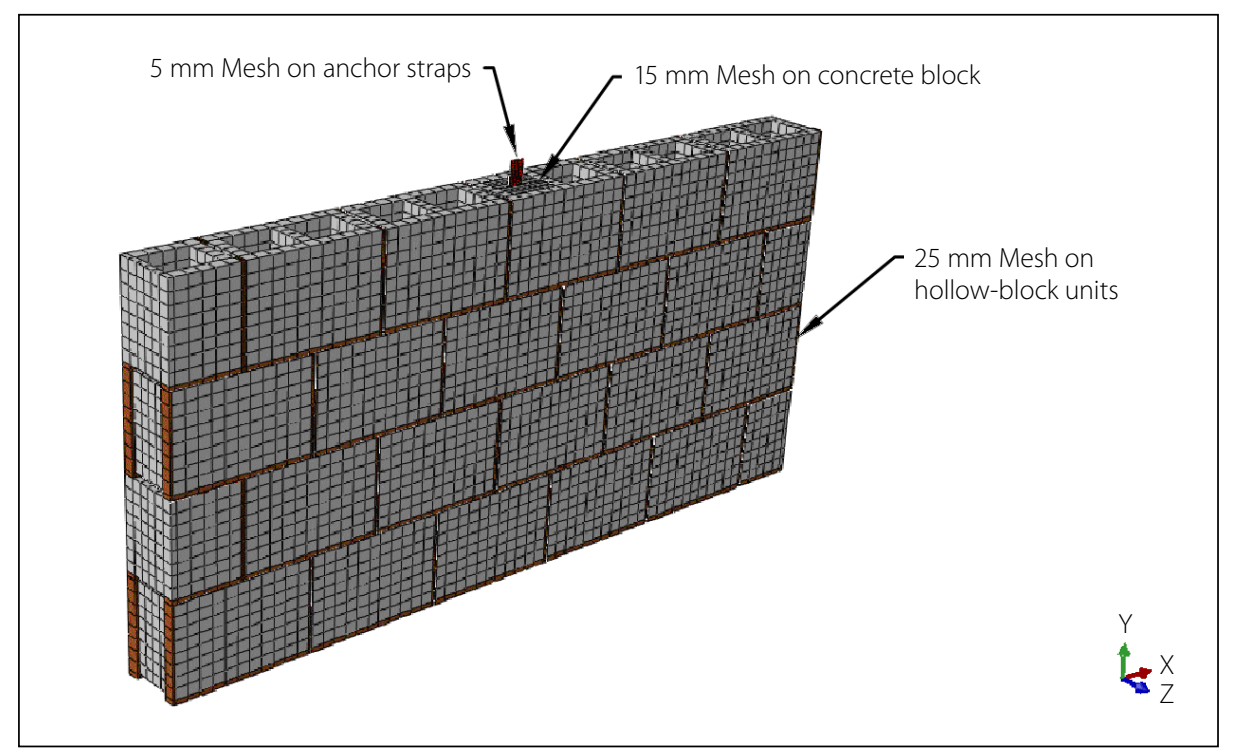

Figure 13 Mesh defined for FEA model of roof anchor system consisting of hollow blocks 
Table 1 Density, Young's Modulus and Poisson's Ratio of masonry constituents

\begin{tabular}{|c|c|c|c|c|c|c|}
\hline \multirow{2}{*}{$\begin{array}{c}\text { Material } \\
\text { group }\end{array}$} & \multicolumn{2}{|c|}{ Density $\left(\mathbf{k g} / \mathrm{m}^{3}\right)$} & \multicolumn{2}{|c|}{ Young's Modulus (MPa) } & \multicolumn{2}{|c|}{ Poisson's Ratio } \\
\hline & $\begin{array}{c}\text { Masonry } \\
\text { units }\end{array}$ & Mortar & $\begin{array}{c}\text { Masonry } \\
\text { units }\end{array}$ & Mortar & $\begin{array}{l}\text { Masonry } \\
\text { units }\end{array}$ & Mortar \\
\hline G1 & 2090 & 2200 & 17900 & $4500^{a}$ & $0.150^{b}$ & $0.150^{b}$ \\
\hline G2 & 2200 & 2200 & 35370 & 9290 & $0.150^{b}$ & $0.150 b$ \\
\hline G3 & 1430 & 2400 & 2170 & 7760 & 0.155 & 0.210 \\
\hline G4 & 1510 & 1860 & 6540 & 1550 & 0.160 & 0.220 \\
\hline
\end{tabular}

In this study, four groups of materials with distinctive mechanical and interfacial bond properties for brick units and mortar were defined in the FEAs to consider the effect of the material properties on the performance of the roof anchor systems. The four material groups designated as "G1" to "G4" were obtained from previous studies. Where some required parameters were not reported in the relevant sources, comparable values were assumed to values obtained from alternative sources.

The first material group (G1) consisted of solid concrete masonry units (commonly used to construct South African $\mathrm{LIHs}$ ) and the parameters of the units were obtained from a study by Fourie (2017). The Poisson's Ratio of the masonry units obtained from Fourie (2017) was unreliable, therefore a more realistic value was assumed. Fourie (2017) only focused on the material parameters of the masonry units, therefore reasonable values for the Young's Modulus, Poisson's Ratio and density of the mortar were assumed for material group "G1". The second material group (G2) consisted of hollow concrete blocks obtained from a study by Santos et al (2017). The density and the Poisson's Ratio of the masonry units and mortar were not reported by Santos et al (2017) and were therefore assumed. The parameters of the third and fourth material groups, designated as "G3" and "G4", respectively, were obtained from Agüera et al (2016) and the masonry units consist of soil-cement blocks.

The values for the densities, Young's Modulus and Poisson's Ratio of the masonry units and mortar for the material data sets are presented in Table 1 . References are provided for the values not provided by the relevant sources. The unknown material densities of masonry units and mortar were assumed a reasonable value of $2200 \mathrm{~kg} / \mathrm{m}^{3}$.

For the simulation of material hardening and softening in the masonry FE model, the behaviour (stress-strain relationship) beyond the elastic range of the masonry units and mortar is required. Whilst the non-linear behaviour of the masonry units and mortar of the material groups "G1" and "G2" was not reported in their respective sources, Santos et al (2017) explained that the complete stress-strain curves for the masonry constituents of material group "G2" were determined for tension and compression from methods for estimating the stressstrain curves of plain concrete as proposed by Zhenhai (2014). These methods were used in their study to simulate testing of masonry prisms through FE modelling. The same methods were adopted in this study to estimate the non-linear behaviour of groups "G1" and "G2". The resultant stressstrain curves are presented in Figure 14. For detailed information on the methods used in determining the stress-strain curves, the reader is referred to Zhenhai (2014). The non-linear material properties of the masonry units and mortar for material groups "G3" and "G4" were adopted from the values reported by Agüera et al (2016).

The parameters adopted for the CDP model that were used to describe the behaviour within the plasticity model were obtained from Santos et al (2017). The parameters are described as follows:

- Dilation angle $(\psi)$ : This parameter is defined by the internal friction of the concrete. The suggested value of $36^{\circ}$ was adopted (Kmiecik \& Kaminski 2011).

- Ratio between yield strength in biaxial state $\left(\sigma_{\mathrm{b} 0}\right)$ and yield strength in uniaxial state $\left(\sigma_{\mathrm{c} 0}\right)$ : This ratio $\left(\sigma_{\mathrm{b} 0} / \sigma_{\mathrm{c} 0}\right)$ was assigned a suggested value of 1.16 (Abaqus 2017).

- Viscosity parameter $(\mu)$ : This parameter defines damage stabilisation that is generally used in implicit models with convergence difficulties. A zero value was adopted.

- Eccentricity parameter $(\rho)$ : The parameter obtained from the DP model defines the yield surface in the meridian plane. A value of 0.1 was adopted for this study.

The steel defined for the anchor strap in the FEA model has a yield strength of $220 \mathrm{MPa}$ and ultimate strength of about $375 \mathrm{MPa}$. The stress-strain relationship of the masonry units and mortar for material

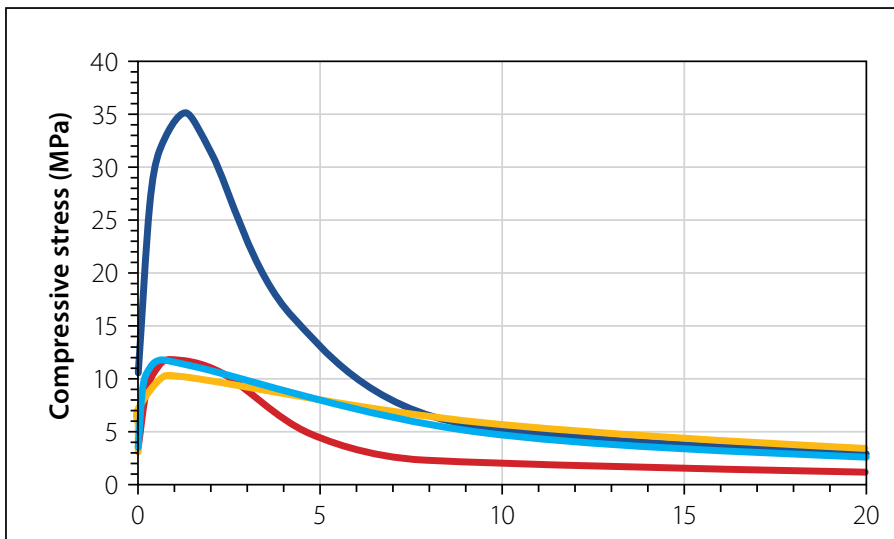

(a)

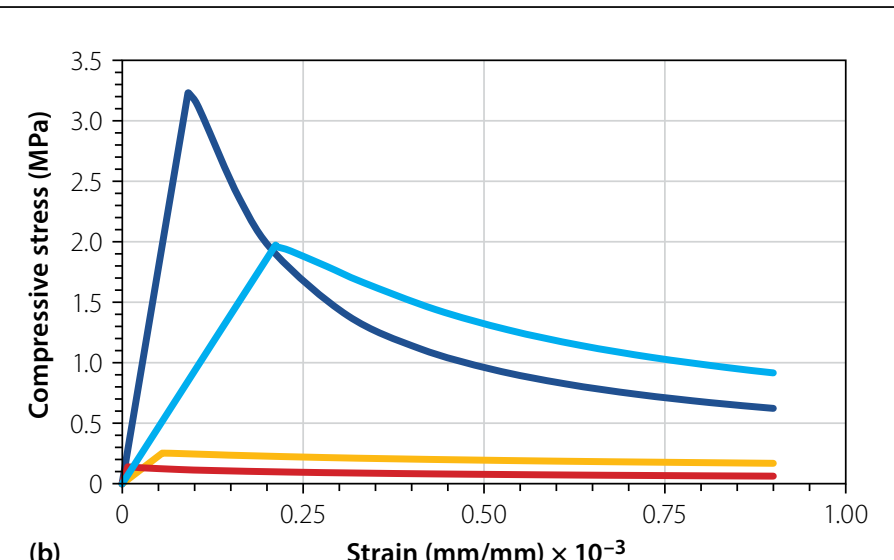

(b)
Strain $(\mathrm{mm} / \mathrm{mm}) \times 10^{-3}$
G1 - Units G G1 - Mortar $-\mathrm{G} 2$ - Units $-\mathrm{G} 2$ - Mortar

Figure 14 Stress-strain curves for masonry units and mortar of material groups "G1" and "G2" as determined from the methods proposed by Zhenhai (2014) for (a) compression and (b) tension 
Table 2 Stress-strain data defined for steel anchor strap (Qi et al 2005)

\begin{tabular}{|c|c|}
\hline \multicolumn{2}{|c|}{$\begin{array}{c}\text { Stress-strain data for the } \\
\text { steel anchor strap }\end{array}$} \\
\hline Stress (MPa) & Strain $\left(\mathbf{m m} / \mathbf{m m} \times \mathbf{1 0}^{-\mathbf{3}}\right)$ \\
\hline 220 & 0 \\
\hline 250 & 5.94 \\
\hline 300 & 16.74 \\
\hline 332 & 22.00 \\
\hline 353 & 25.75 \\
\hline 370 & 51.50 \\
\hline 374 & 105.20 \\
\hline
\end{tabular}

the steel was adopted from Qi et al (2005) as presented in Table 2.

The unit-mortar bond interface between adjacent REs was defined by surface-surface contact interaction through the following contact relationships:

- Tangential behaviour to accommodate friction in masonry joints

- Hard contact (prevents penetration and allows for separation of surfaces)

- Cohesive behaviour to accommodate joint stiffness

- Damage initiation and evolution to accommodate stiffness degradation. The tensile and shear response of the joints was defined through traction separation laws. A friction coefficient of 0.75 was defined as adopted from Abdulla et al (2017). A dummy stiffness was defined to represent the elastic response of the masonry joint interface and to prevent interpenetration of the REs. The Young's Modulus of the mortar for each material group was adopted as the elastic response of the masonry joints in the normal (tensile) direction, while the elastic response of the joint interface in the first and second shear directions is equal to the Shear Modulus of the mortar. The masonry joint stiffness (K) for each material group is summarised in Table 3. The subscripts "n", "s", and "'t" represent the normal, first-, and second shear directions, respectively.

Damage initiation of the joint interfaces, as summarised in Table 4, was defined through a quadratic stress criterion that follows the initial linear response. The traction at damage initiation is defined by the parameters designated as " $t$ ". The fracture energy of the masonry joints was defined through the parameters " $\mathrm{G}_{\mathrm{I}}$ ", " $\mathrm{G}_{\mathrm{II}}$ ", and " $\mathrm{G}_{\mathrm{III}}$ " that represent the fracture energies in the normal, first and second shear directions, respectively. The critical mixedmode fracture energy is obtained from

Table 3 Cohesive properties defined for masonry joints per material group

\begin{tabular}{|c|c|c|c|}
\hline \multirow{2}{*}{ Material group } & \multicolumn{3}{|c|}{ Cohesive properties of joints } \\
\hline & $\mathrm{K}_{\mathrm{nn}}\left(\mathrm{N} / \mathrm{mm}^{3}\right)$ & $\mathrm{K}_{\mathrm{ss}}\left(\mathrm{N} / \mathrm{mm}^{3}\right)$ & $\mathrm{K}_{\mathrm{tt}}\left(\mathrm{N} / \mathrm{mm}^{3}\right)$ \\
\hline G1 & 4500 & 1960 & 1960 \\
\hline G2 & 9290 & 4040 & 4040 \\
\hline G3 & 7760 & 3210 & 3210 \\
\hline G4 & 1550 & 640 & 640 \\
\hline
\end{tabular}

Table 4 Damage interface properties defined per material group

\begin{tabular}{|c|c|c|c|c|c|c|c|}
\hline \multirow{2}{*}{$\begin{array}{c}\text { Material } \\
\text { group }\end{array}$} & \multicolumn{7}{|c|}{ Quadratic damage properties with mixed-mode evolution } \\
\hline & $\begin{array}{c}t_{n} \\
(\mathrm{MPa})\end{array}$ & $\begin{array}{c}t_{s} \\
(\mathrm{MPa})\end{array}$ & $\begin{array}{c}t_{t} \\
(\mathrm{MPa})\end{array}$ & $\begin{array}{c}\mathbf{G}_{1} \\
(\mathbf{N} / \mathrm{mm})\end{array}$ & $\begin{array}{c}\mathbf{G}_{\mathrm{II}} \\
(\mathbf{N} / \mathrm{mm})\end{array}$ & $\begin{array}{c}\mathbf{G}_{\mathrm{III}} \\
(\mathrm{N} / \mathrm{mm})\end{array}$ & $\boldsymbol{\eta}$ \\
\hline G1 & $0.25^{\mathrm{a}}$ & 0.17 & 0.17 & $0.012^{b}$ & $0.028 \mathrm{~b}$ & $0.028^{b}$ & 2 \\
\hline G2 & 1.47 & 0.23 & 0.23 & $0.012^{b}$ & $0.028^{b}$ & $0.028^{b}$ & 2 \\
\hline G3 & $0.20^{\mathrm{a}}$ & $0.30^{c}$ & $0.30^{c}$ & $0.012^{b}$ & $0.028^{b}$ & $0.028^{b}$ & 2 \\
\hline G4 & $0.20^{\mathrm{a}}$ & $0.30^{c}$ & $0.30^{c}$ & $0.012^{b}$ & $0.028^{b}$ & $0.028^{b}$ & 2 \\
\hline & Refere & a: $\operatorname{Re}$ & Supta & b: Ans & (2014) & S (2005) & \\
\hline
\end{tabular}

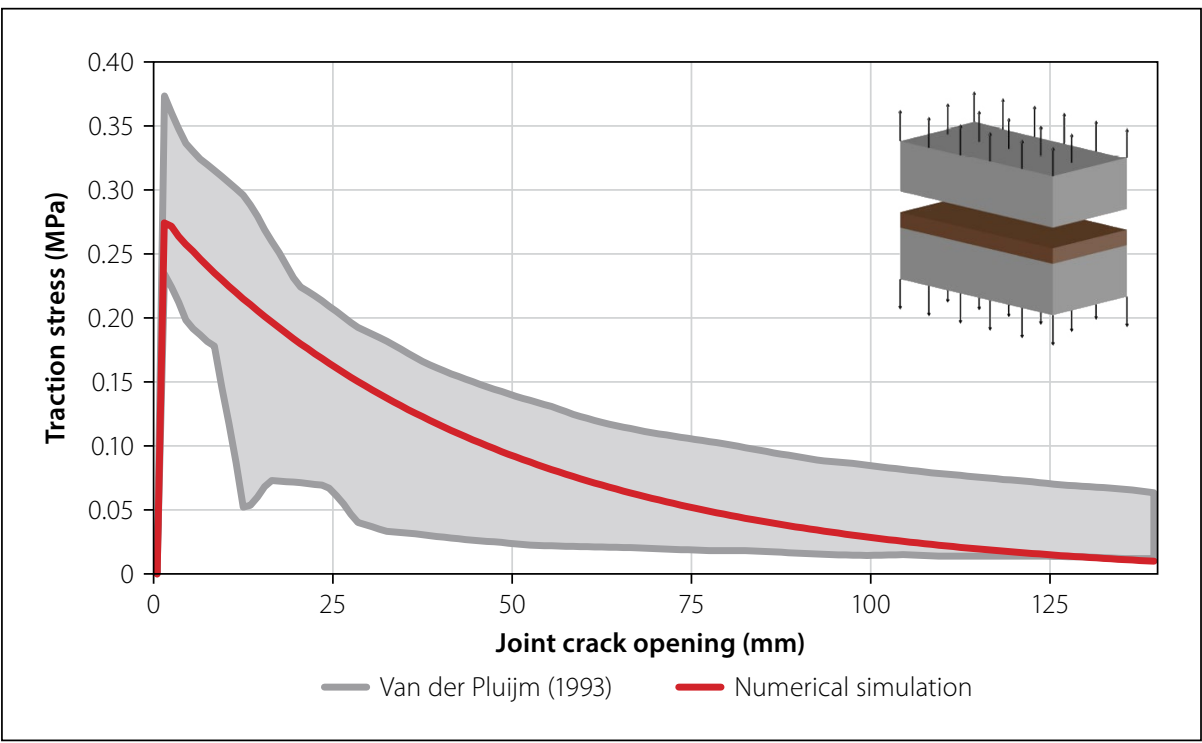

Figure 15 Comparison between numerical (red line) and experimental (grey envelope) results for small-scale masonry specimens subject to direct tension

the Benzeggagh-Kenane (BK) law with an exponent $(\eta)$ taken as 2 by assuming brittle behaviour (Abdulla et al 2017).

Note that the interfacial bond strength of material group "G2" relates to concrete hollow-block masonry, while the interfacial bond strengths of material groups "G1", "G3" and "G4" were obtained from a study conducted on the bond strength of soil-cement masonry (Reddy \& Gupta 2006), and the values are fairly lower $(0.2-0.25 \mathrm{MPa}$ compared to $1.47 \mathrm{MPa}$ ). Despite the lower bond strength values being based on soil-cement blocks, they were also utilised in the hollowblock FE models. This is deemed reasonable, as it can be regarded as the equivalent of accounting for poor quality mortar or workmanship, resulting in a weak interface.
A friction interaction with a coefficient of friction of 0.5 was assigned between the steel and the masonry wall that is in range with the values suggested by Rabbat and Russell (1985) for friction between steel and concrete. The bonding of the anchor embedded in the masonry joint was defined through a contact interaction property. The properties were adopted from Rabbat and Russell (1985) and were defined as follows:

- Tangential behaviour to accommodate friction between the anchor mortar joint with a friction coefficient of 0.5 .

- Cohesive behaviour to accommodate anchor bond stiffness. The stiffness value is based on the underlying elements by using the default value of Abaqus. 


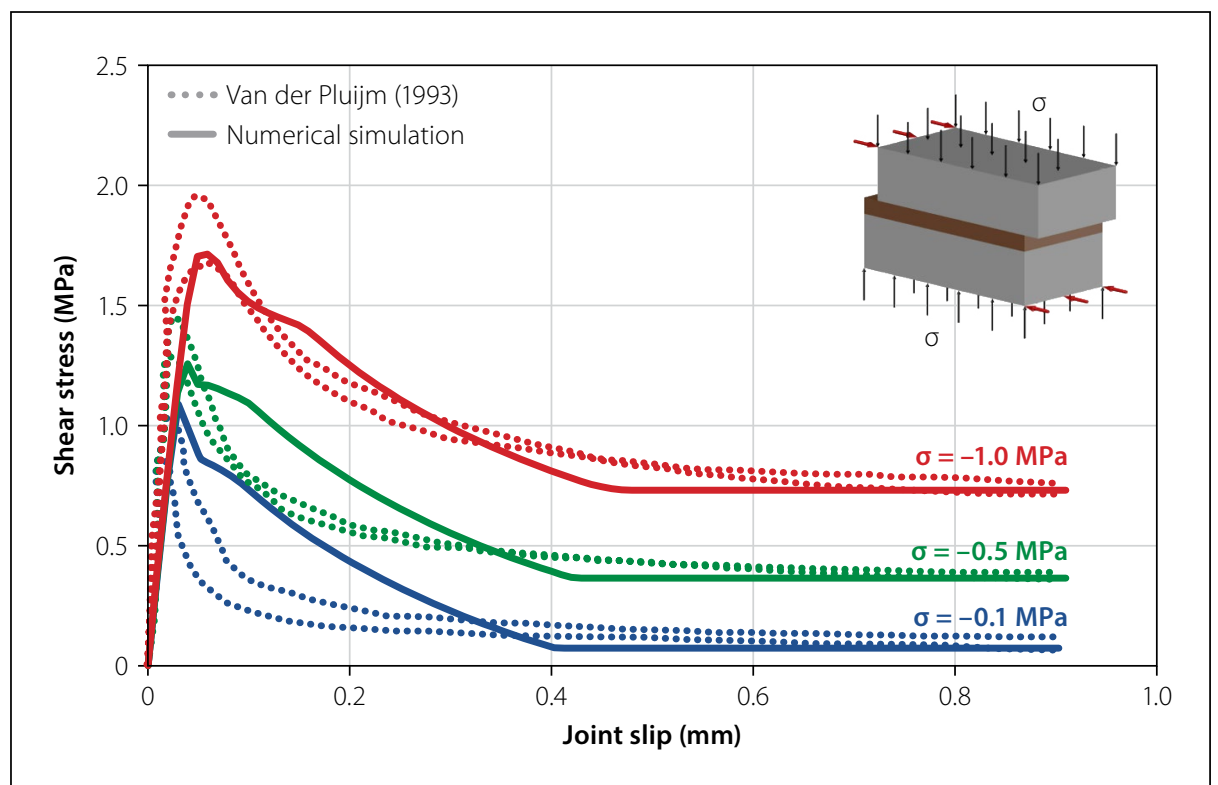

Figure 16 Comparison between numerical (solid lines) and experimental (dotted lines show a range of values) results for small-scale masonry specimens subject to shear for three values of initial compressive stress $0.1,0.5$ and $1.0 \mathrm{MPa}$

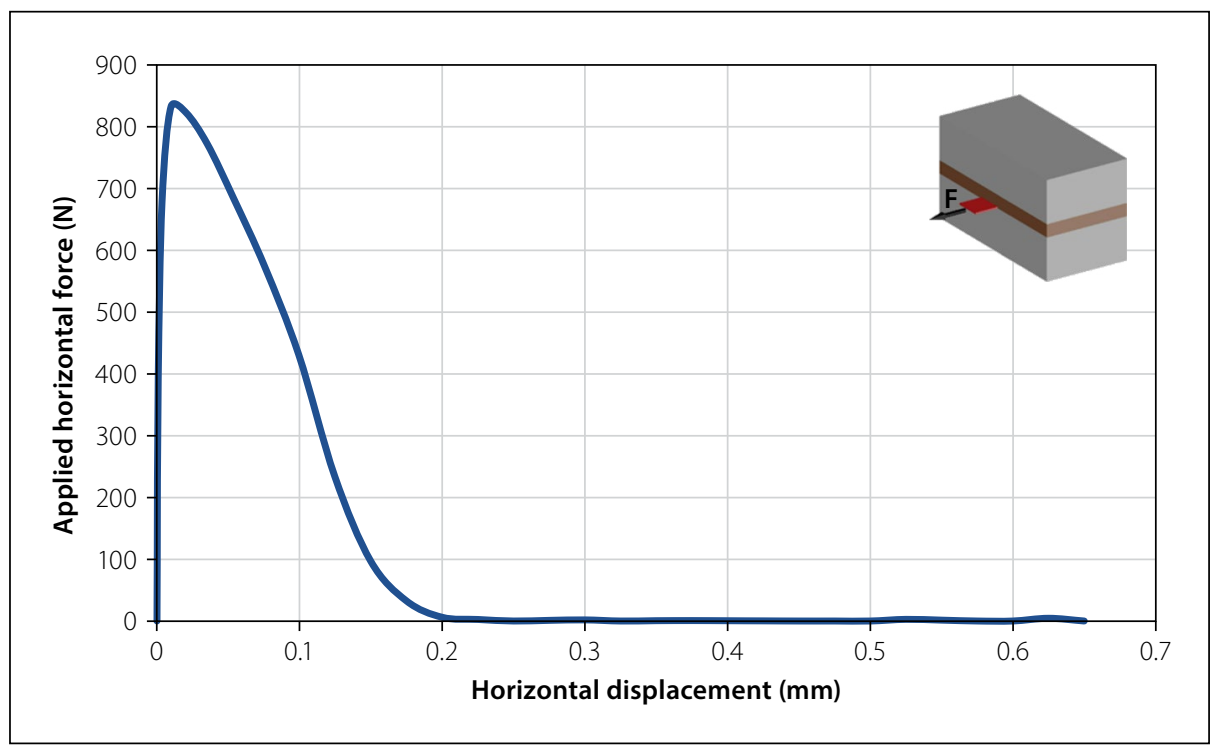

Figure 17 Small-scale anchor pull-out test to validate anchor bond simulation

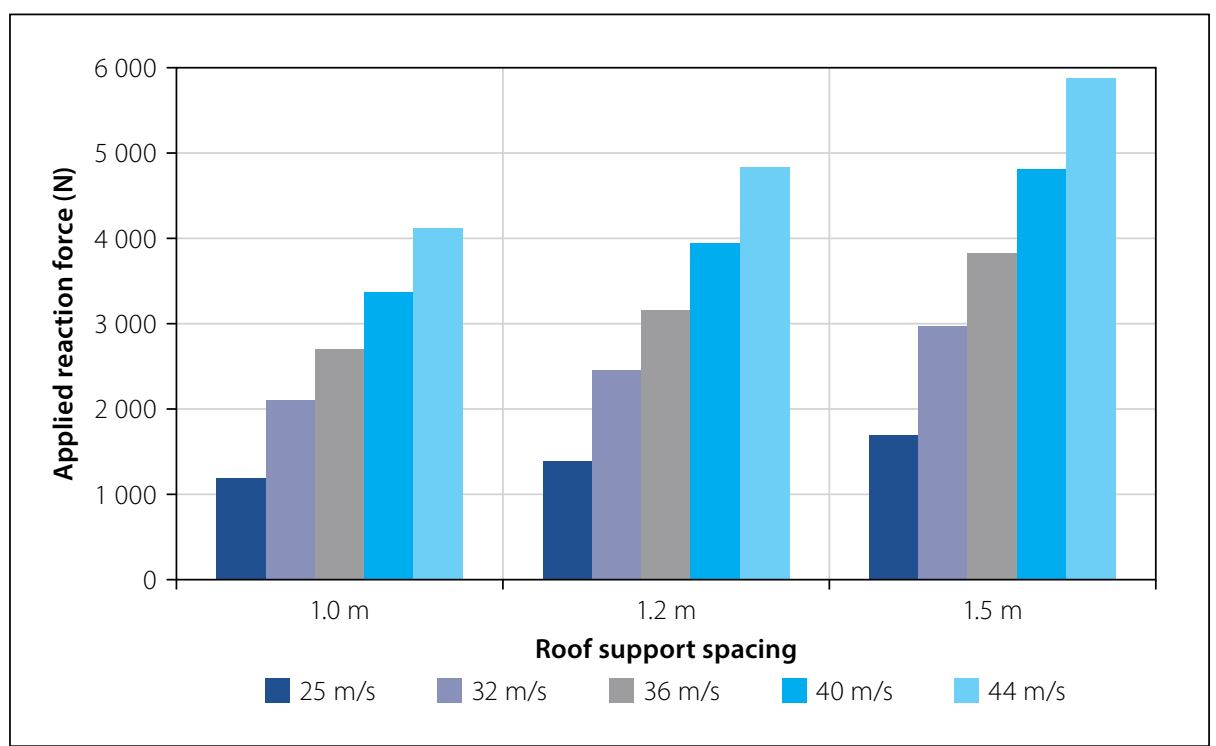

Figure 18 Vertical reaction forces obtained the roof anchors at the roof support spacings, and peak basic wind speeds considered
Damage initiation and evolution that represent the degradation of anchor bond strength. A bond strength of $0.39 \mathrm{MPa}$ and fracture energy of $25 \mathrm{~N} / \mathrm{m}$ were defined.

\section{Validation of modelling approach}

Small-scale FEA models were used to verify the behaviour of the modelling strategy by comparing the result with experimental results obtained by Van der Pluijm (1992). Figures 15 and 16 show the comparison between the numerical and experimental results for the tensile and shear behaviour of the masonry joints, respectively.

A small-scale FEA that simulates an anchor pull-out test was conducted to validate the contact interaction that represents the anchor bond - the horizontal section of the anchor was modelled and embedded $70 \mathrm{~mm}$ between two masonry units by adopting the material properties of material group "G1", and a horizontal "pulling" force was applied to the anchor. The peak force that will cause the anchor bond to fail (referred to as the anchor pull-out resistance) is determined from the horizontal force versus horizontal displacement diagram extracted from the FEA software. The results indicate a peak horizontal force of about $830 \mathrm{~N}$, as presented in Figure 17.

Hand calculations were used to validate the resistance of the defined contact interaction. An anchor pull-out resistance $\left(H_{R}\right)$ of $819 \mathrm{~N}$ was calculated per Equation 1, which is in close agreement with the result obtained from Figure 17.

$H_{R}=c \times A_{b}$

Where:

$H_{R}$ is the determined peak resistance (horizontal pulling force) given in Newtons

$c$ is the cohesion or bond strength defined as 0.39 MPa (Rabbat \& Russell 1985)

$A_{b}$ is the calculated area of the bond surface that is $2100 \mathrm{~mm}^{2}(70 \mathrm{~mm} \times 30 \mathrm{~mm})$

\section{RESULTS AND DISCUSSION}

\section{Reaction forces determined at the roof anchors}

Figure 18 shows the maximum reaction forces obtained at the roof anchor systems for the basic wind speeds considered at $1.0 \mathrm{~m}, 1.2 \mathrm{~m}$, and $1.5 \mathrm{~m}$ roof support spacing. The maximum reaction forces were obtained from the range of LIH models that were considered in this study. 
The response of the roof anchor systems consisting of a solid brick wall

The load-displacement curves presented in Figure 19 show the applied force versus the free-end slip of the solid brick wall's anchor strap for the material groups defined in this study. The ultimate capacity of the roof anchor system is represented by the maximum reaction force obtained throughout the loading history.

From Figure 19 it is evident that the limiting resistance of about $2100 \mathrm{~N}$ corresponds to material data groups " $\mathrm{G} 2$ " and "G3". The ultimate failure of the roof anchor system was achieved through pull-out of the anchor strap as the bond strength was overcome. The free-end slip of the anchor is demonstrated in Figure 20. It was further noted that the resistance of the roof anchor system is affected by the material properties of the masonry constituents and the brick-mortar bond strength.

The damage variable was used to capture the degree of damage in the elements of the masonry brick units and mortar throughout the loading history. Figure 21 shows the results of material group "G1" at the instance of roof anchor pull-out.

The results show that material damage in the masonry is present at the instant of roof anchor pull-out. This suggests that cracks in the masonry wall will occur before anchor pull-out and damage are visible on the masonry walls. A maximum damage variable of 0.56 was observed. This suggests that the masonry is partially damaged while the anchor strap is still fixed. The results agree with the nature of damage presented in Figure 1.

\section{The response of the roof anchor systems consisting of a hollow-block wall}

The load-displacement curves presented in Figure 22 show the applied force versus the free-end slip of the hollow-block wall's anchor strap.

Material groups "G1" and "G4" failed through masonry joint failure. Figure 23(a) illustrates a section through the wall that indicates the masonry joint failure. The corresponding load-displacement curves from Figure 22 showed gradual stiffness degradation as failure occurs in the masonry joints. The curves flattened out after the peak capacity of the masonry joints was attained.

Material groups "G2" and "G3" failed through anchor pull-out, the corresponding load-displacement curves from

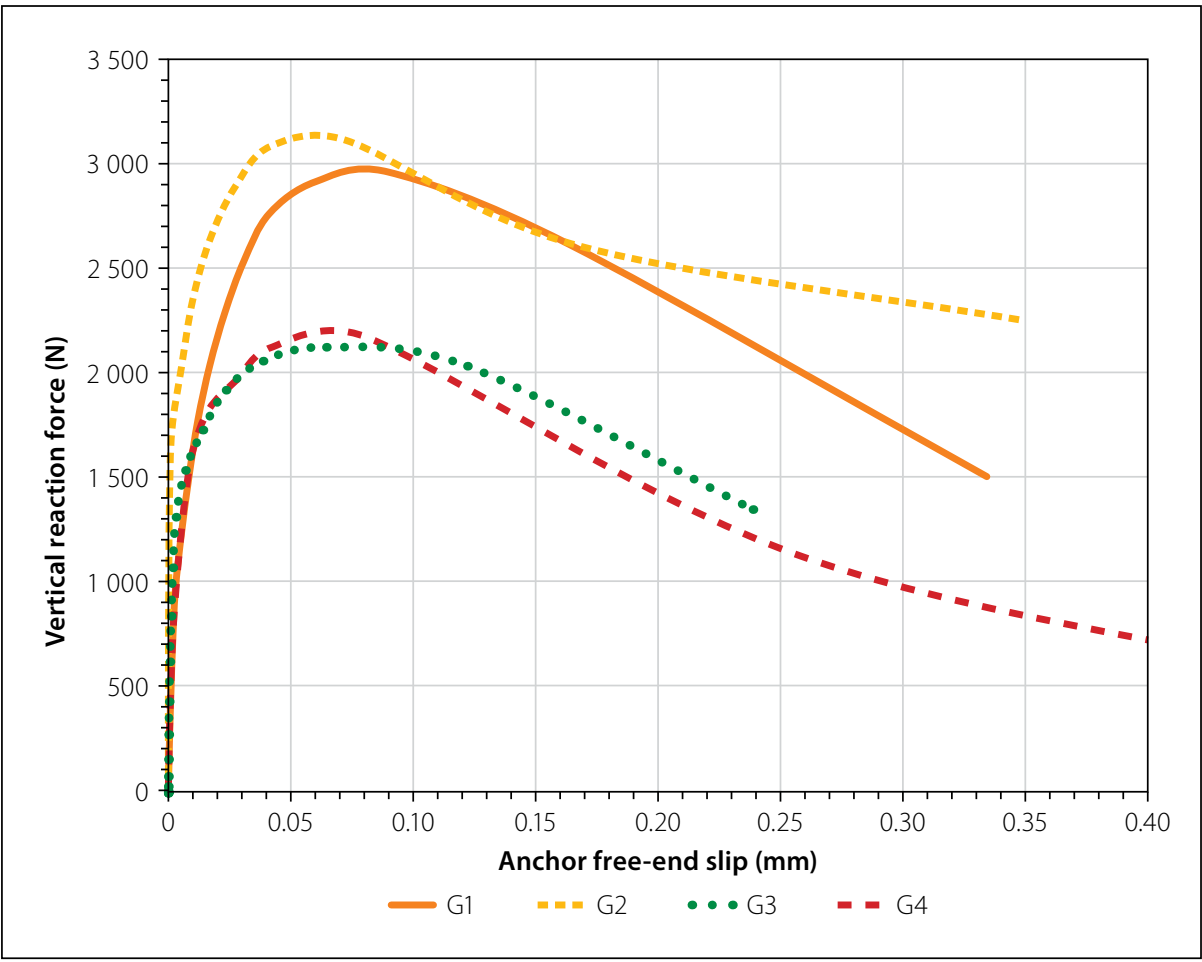

Figure 19 Response of the roof anchor system for the material groups defined in this study

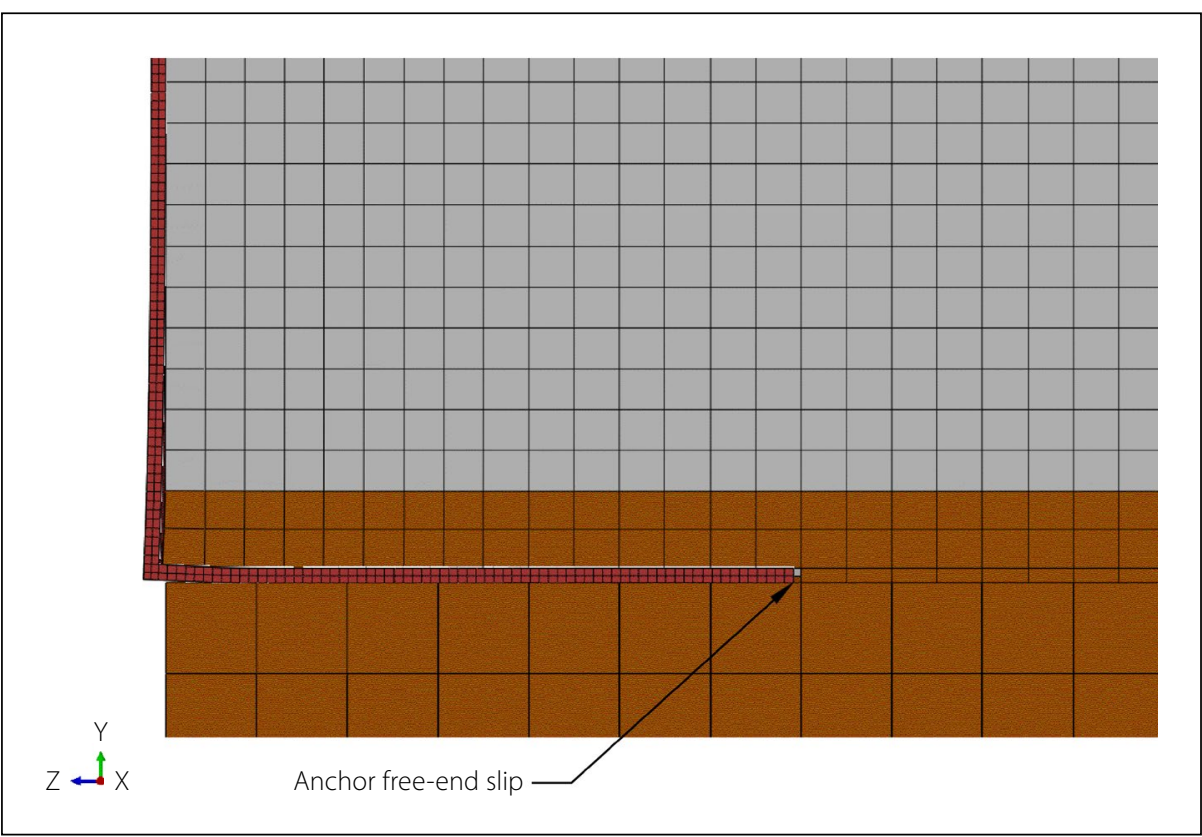

Figure 20 Section indicating the anchor free-end slip resulting from an anchor bond failure

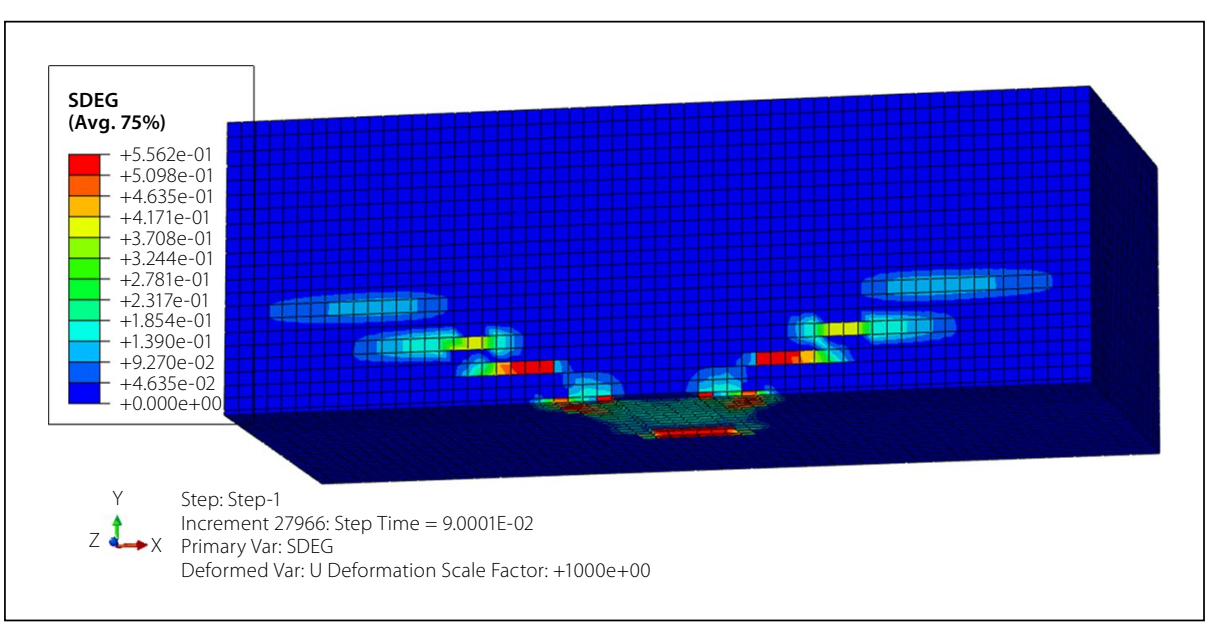

Figure 21 Damage variable in brick and mortar recorded at the instant of roof anchor pull-out 


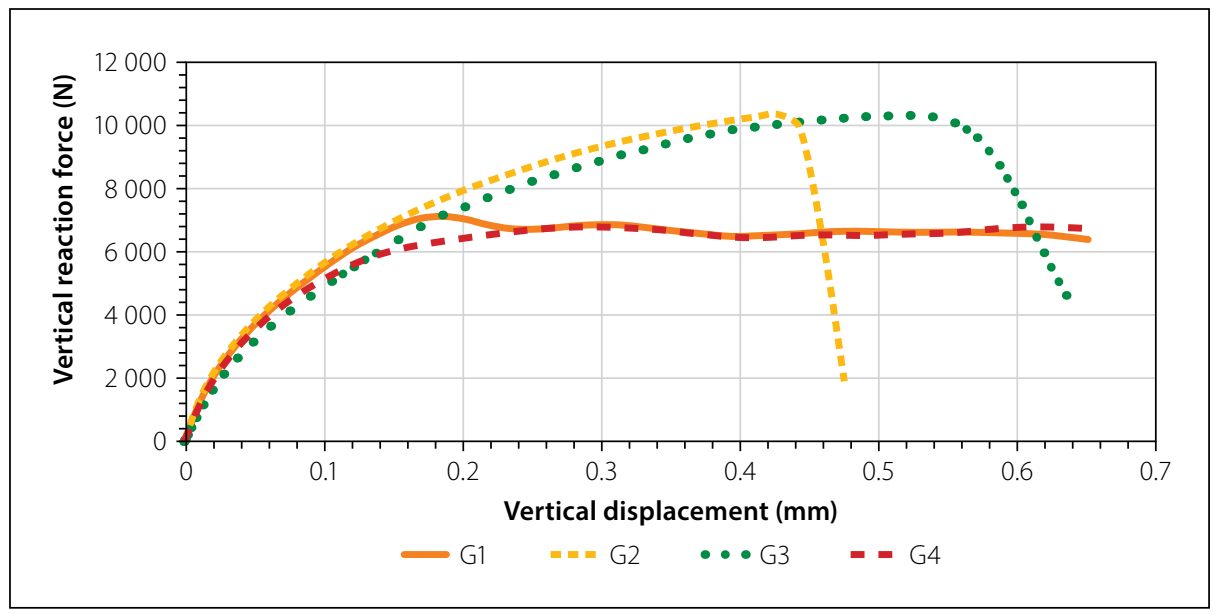

Figure 22 Response of the roof anchor system consisting of hollow-block masonry walls for the material groups defined in this study

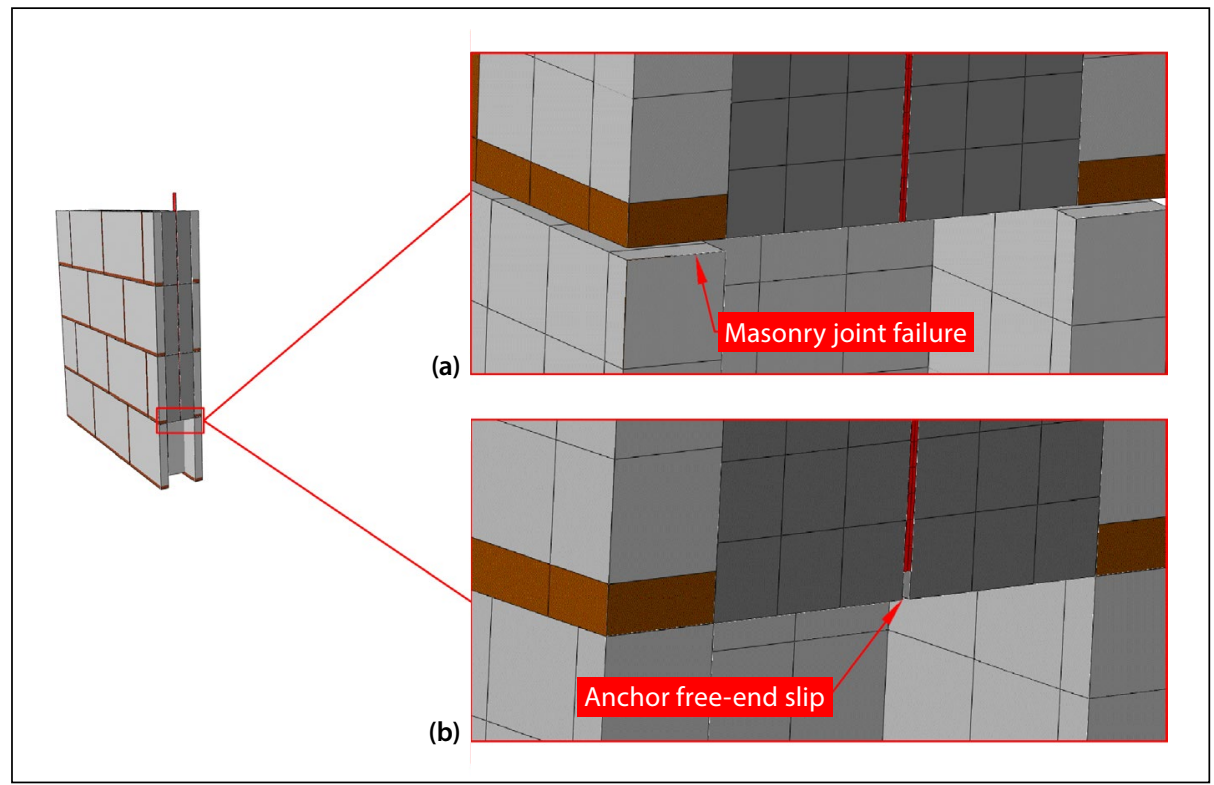

Figure 23 Failure mechanisms observed in hollow block walls: (a) material groups "G1" and "G4", (b) material groups "G2" and "G3"

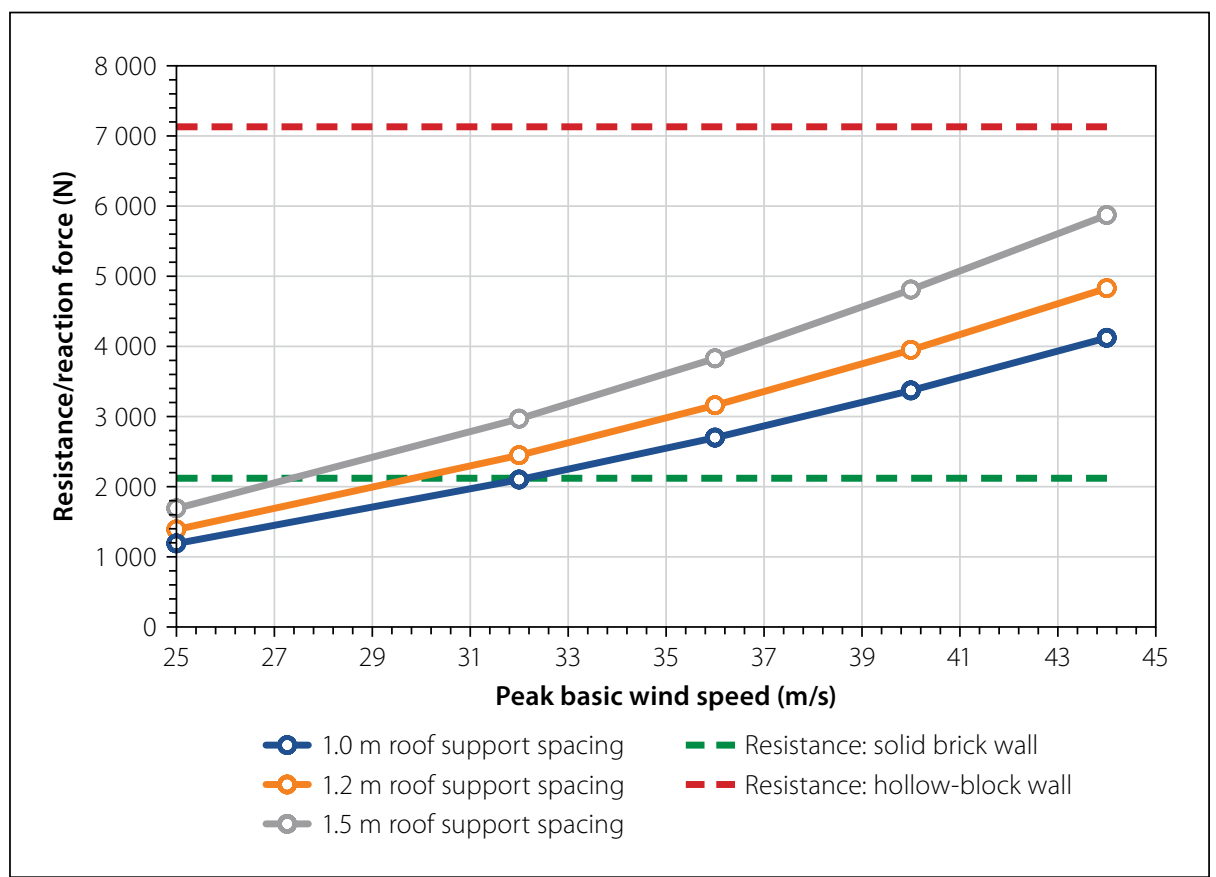

Figure 24 Predicted resistance of the roof anchor systems compared to reaction forces expected at the roof anchor systems
Figure 22 exhibited similar behaviour to that of a pull-out test conducted for a bar embedded in concrete, as proposed by Zhenhai (2014). Figure 23(b) illustrates a section through the wall that indicates the free-end slip observed as the anchor pulls out of the concrete infill.

\section{Predicted adequacy of the roof anchor systems}

Figure 24 presents the least resistance obtained from the FEA models, representing the capacity of roof anchor systems, as well as the reaction forces determined at the roof anchor systems against basic wind speed for different roof support spacings.

The following observations were made from the diagram:

- Failure of the roof anchor system for solid brick walls occurs at a basic wind speed of about $27 \mathrm{~m} / \mathrm{s}$ for LIHs with roof support spacings of $1.5 \mathrm{~m}$.

- Failure of the roof anchor system for solid brick walls occurs at a basic wind speed of about $30 \mathrm{~m} / \mathrm{s}$ for LIHs with roof support spacings of $1.2 \mathrm{~m}$.

- Failure of the roof anchor system for solid brick walls occurs at a basic wind speed of about $32 \mathrm{~m} / \mathrm{s}$ for LIHs with roof support spacings of $1.0 \mathrm{~m}$.

- Overall, the roof anchor system for solid brick walls lacks sufficient resistance at the maximum basic wind speed that is expected to occur during the design life of South African LIHs. The peak basic wind speeds at failure agree with the suggestion that structures with a lack of engineering input generally fail at wind speeds of about $30 \mathrm{~m} / \mathrm{s}$ as suggested by Mahachi et al (2018).

- The results show that the resistance of the roof anchor system for hollow-block walls provided sufficient resistance at the roof anchors for the range of peak basic wind speeds and roof support spacings considered.

\section{CONCLUSION}

This paper investigated the structural performance of the roof anchor systems for LIHs with light roofs that are supported on single-leaf masonry walls as prescribed by SANS 10400-K (SANS 2015). The investigation was carried out through a quantitative research approach. FEA models were used to simulate the roof anchor system. The resistance predicted from the FEA models was compared to the expected reaction forces at the roof anchors that were determined 
from a series of static analyses. The reaction forces that are expected to occur at the roof anchor systems are based on South Africa's strong wind climate. SANS 10160-3 (SANS 2018) was used to calculate the wind loading on the roofs.

This study predicted that the prescribed anchoring method used in conjunction with single-leaf solid brick walls are inadequate for LIHs and failures are likely to occur during strong wind events. The results predicted that roof anchor failures might occur at basic wind speeds between $27 \mathrm{~m} / \mathrm{s}$ and $32 \mathrm{~m} / \mathrm{s}$ for LIHs situated in areas with regular vegetation or buildings, depending on the roof support spacing. Failures might occur at lower basic wind speeds for LIHs located in open areas with low vegetation. This study recommends further research for developing robust roof anchor systems for single-leaf solid brick walls, and that the local codes be amended accordingly.

This study showed that the roof anchor systems prescribed for hollow-block walls performed well. The resistance of the roof anchor systems provided sufficient resistance against the expected reaction forces at the roof anchors during strong wind events.

\section{REFERENCES}

Abaqus 2017. Abaqus documentation. Providence, RI: Dassault Systèmes.

Abdulla, K F, Cunningham, L S \& Gillie, M 2017. Simulating masonry wall behaviour using a simplified micro-model approach. Engineering Structures, 151: 349-365.

Agüera, N, Tornello, M Frau, C D 2016. Structural response of unreinforced masonry walls. Journal of Civil Engineering and Architecture, 10(2): 219-231.

Angelillo, M 2014. Mechanics of masonry structures. Udine, Italy: International Centre for Mechanical Sciences.
BS (British Standard) 2005. BS EN, 1996-1-1 2005. Eurocode 6: Design of Masonry Structures, Part11: General Rules for Reinforced and Unreinforced Masonry Structures. Brussels, Belgium: European Committee for Standardization.

Fourie, J 2017. Characterisation and evaluation of the mechanical properties of alternative masonry units. MEng Dissertation. Stellenbosch University. https://scholar.sun.ac.za/handle/10019.1/100880.

Goliger, A M 2002. Development of a wind damage and disaster risk model for South Africa. PhD Thesis. Stellenbosch University. https://scholar.sun.ac.za/ handle/10019.1/70419.

Kmiecik, P \& Kaminski, M 2011. Modelling of reinforced concrete structures and composite structures with concrete strength degradation taken into consideration. Archives of Civil and Mechanical Engineering, 11: 623-636.

Mabuya, B \& Scholes, M 2020. The three little houses: A comparative study of indoor and ambient temperatures in three low-cost housing types in Gauteng and Mpumalanga, South Africa. Environmental Research and Public Health, 17(10): 3524. https://www.mdpi. com/1660-4601/17/10/3524\#.

Mahachi J, Bradley, R \& Goliger, A 2018. Windstorm damage to houses: Planning and design considerations. Proceedings, Out-of-the-Box Human Settlements Conference, October 2018, CSIR, Pretoria.

Mahachi, J 2021. Development of a construction quality assessment tool for houses in South Africa. Acta Structilia, 28(1): 91-116. doi: 10.18820/24150487/as28i1.4.

Ogunfiditimi, O 2008. Assessment of structural quality of houses delivered through the people's housing process in South Africa. MTech Dissertation. University of Johannesburg.

Oliveira, A, Casali, J \& Jr, L R P 2009. A study of the structural behavior of masonry prisms and wallettes built with a new type of concrete block. Proceedings, 11th Canadian Masonry Symposium, 31 May 3 June 2009, Toronto, Canada.
Qi, C, Ma, Z D, Kikuchi, N, Pierre, C, Wang, H \& Raju, B 2005. Fundamental studies on crashworthiness design with uncertainties in the system. Proceedings, 2005 SAE World Congress and Exhibition, 11-14 April 2005, Detroit, MI. SAE Technical Paper.

Rabbat, B G \& Russell, H G 1985. Friction coefficient of steel on concrete or grout. Journal of Structural Engineering (US), 111(3): 505-515.

Reddy, B V V \& Gupta, A 2006. Tensile bond strength of soil-cement block masonry couplets using cement-soil mortars. Journal of Materials in Civil Engineering, 18(1): 36-45.

SANS (South African National Standard) 2011. SANS 10400-L: 2011. The Application of the National Building Regulations. Part L: Roofs. Pretoria: SABS Standards Division.

SANS 2015. SANS 10400-K: 2015. The Application of the National Building Regulations Part K: Walls. Pretoria: SABS Standards Division.

SANS 2018. SANS 10160-3: 2018. Basis of Structural Design and Actions for Buildings and Industrial Structures Part 3: Wind Actions. Pretoria: SABS Standards Division.

Santos, C, Alvarenge, R, Ribeiro, J, Castro, L, Silvia, R, Santos, A et al 2017. Numerical and experimental evaluation of masonry prisms by finite element method. Revista IBRACON de Estruturas e Materiais, 10(2): 477-508.

Sarhosis, V, Garrity, S W \& Sheng, Y 2015. Influence of brick-mortar interface on the mechanical behaviour of low bond strength masonry brickwork lintels. Engineering Structures, 88: 1-11.

Van der Pluijm, R 1992. Material properties of masonry and its components under tension and shear. Proceedings, 6th Canadian Masonry Symposium 15-17 June 1992, Saskatoon, Canada, pp 675-686.

Zhenhai, G 2014. Principles of Reinforced Concrete. 1st ed. Oxford: Elsevier.

Zunguzane, N, Smallwood, J \& Emuze, F 2012. Perceptions of the quality of low-income houses in South Africa: Defects and their causes. Acta Structilia, 19(1): 19-38. 